\title{
A LARGE-SCALE PERSPECTIVE ON ECOSYSTEMS
}

\author{
Hiroshi Mizutani \\ Laboratory of Biogeochemistry and Sociogeochemistry, \\ Mitsubishi-Kasei Institute of Life Sciences, \\ 11 Minamiooya, Machida, Tokyo 194, JAPAN.
}

\begin{abstract}
Interactions between ecological elements must be better understood in order to construct an ecological 1 ife support system in space. An index was devised to describe the complexity of material cyclings within a given ecosystem. It was then applied to the cyclings of bioelements in various systems of material cyclings including the whole Earth and national economies. The results show interesting characteristics of natural and manmade systems.
\end{abstract}

\section{INIRODUCTION}

In order to construct an ecologically based life support system in space, we must first understand the interactions of ecological elements in ecosystems on the Earth. Without knowledge of these interactions, a mere combination of the elements may not result in anything resembling what we originally intended to create. Its necessity becomes more manifest when we try to envision construction of a completely closed, regenerative life support system that can accommodate tens of thousands of people.

Then, do we have the understanding? I am afraid that we do not. We do not know, either in theory or in practice, how the elements in an ecosystem interact. The environmental problems we face today illustrate the inadequacy of the understanding $/ 1 /$.

Natural ecosystems develop continuously through a process called succession. The culmination of the succession is a stabilized ecosystem in which maximum protection from perturbations is achieved. There, nutrient cyclings are more or less closed, while they are open before reaching the stabilized condition.

Closed nutrient cycling is not very productive $/ 2 \%$. In the past, man has generally been interested in obtaining maximum production from ecosystems by developing and maintaining early successional types of ecosystems. This tendency is deeply rooted in the makeup of our science and society, and is a principal cause for the present environmental problems of anthropogenic origin.

This nature of ecosystems presents a conflict we have to face in constructing a closed, ecological life support system. Because we would like it to have a high production rate for life support materials such as molecular oxygen, food, clean water, and fresh air on one hand, and also would like it to be closed and stable on the other hand. We need to recognize, if we are to be successful in establishing an ecologically based life support system, that we are going to have to deal with a system with which we are not very familiar. Therefore, it is of paramount importance to have a perspective viewpoint on what, materialwise, natural ecosystems do and how man-made systems are different from natural ones.

\section{SYSTEMS OF MATERIAL CYCLINGS, NATURAL AND ARTIFICIAL}

In an ecological system there are various elements that transfer, transform, and/or store physicochemical resources such as oxygen, organic compounds, water, and carbon dioxide. In order to put various systems of material cyclings in perspective, these elements are grouped according to their activity. For instance, a pine tree in a natural forest may be regarded as an element that transforms water and carbon dioxide to molecular oxygen and organic matter. Likewise, a factory that burns oil is an element that transforms organic carbon to inorganic carbon. Unlike the tree, the location of the factory and the kind of products it yields are largely determined by reasons unrelated to ecological and biological reasons. However, its very existence certainly affects the carbon and other material cyclings. Details of the classifying method are given elsewhere $/ 3,4 /$. 


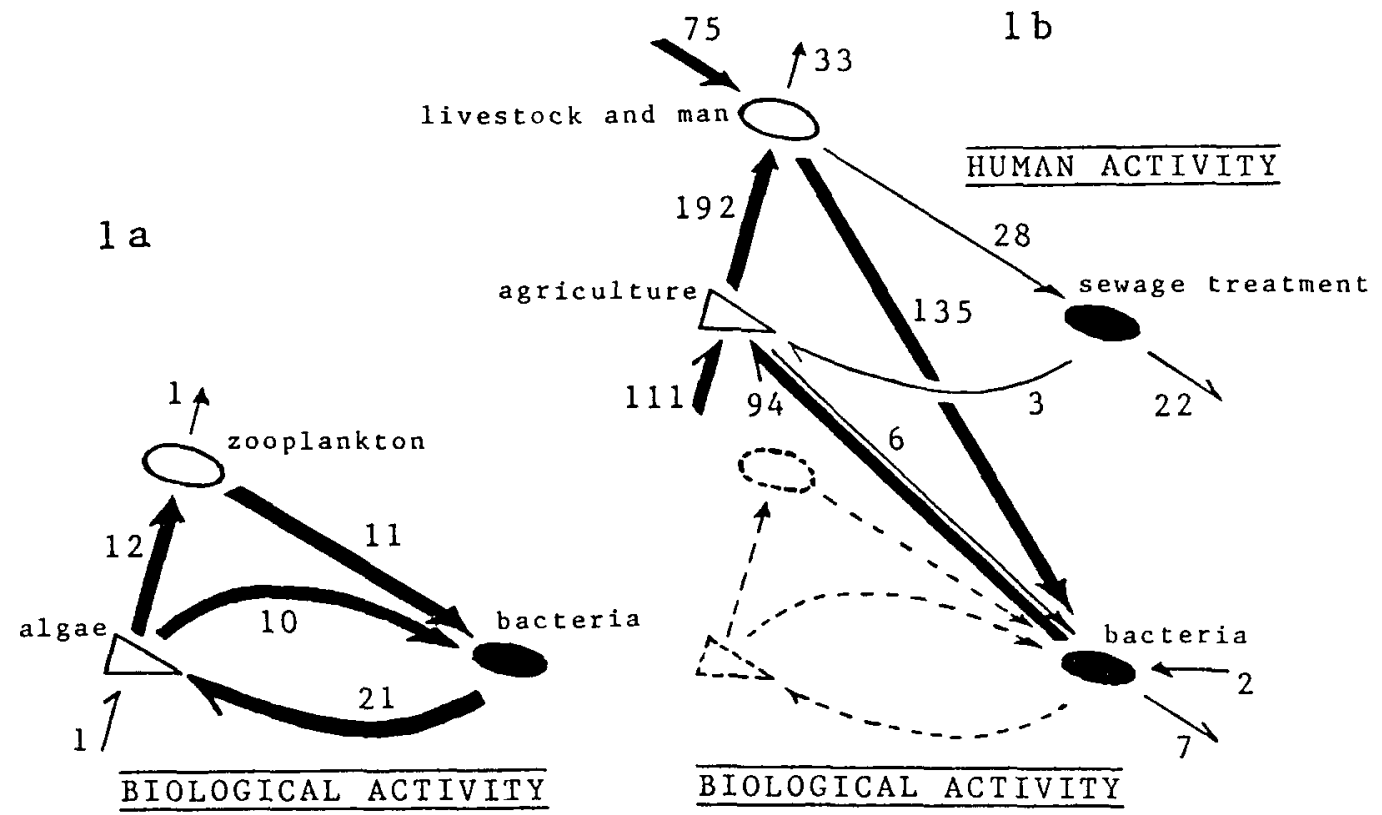

Fig. 1. Natural and man-made phosphorus cycles. Names indicate representative elements that are responsible for the transforming activity. Imbalance between inputs to and outputs from each transforming activity results 1) from the accumulation or the loss of phosphorus from the ecosystem and/or 2) from an incomplete account of the phosphorus budget. Shape of arrowhead distinguishes the kind of phosphorus: $\longrightarrow$ for a flow of organic phosphorus and $\longrightarrow$ for a flow of inorganic phosphorus. Fig. la the cycle in the trophogenic zone of a eutrophic lake: the numbers indicate phosphorus flux relative to the amount of incoming inorganic phosphate; thick arrows stand for a flux 10 times larger than the incoming phosphate; the basis for the figure is from Rigler /5/. Fig. $1 \mathrm{~b}$ UK phosphorus economy: all numbers refer to thousands of tons $\mathrm{P} /$ year; data are based on Bowman $/ 6 /$; the annual flow of 75 kilotons $P$ or more is indicated by a thick arrow, while that between 33 and 2 kilotons $P$ by a thin arrow; flows less than 2 kilotons $P$ are not shown.

Figure 1 compares the phosphorus cycle in the trophogenic zone of a eutrophic lake (1a) with the phosphorus economy of the United Kingdom (1b). In this particular model eutrophic lake, one unit of inorganic phosphorus enters the ecosystem and the same quantity of phosphorus sediments in the form of zooplankton feces. The amount of phosphorus that moves along with the four paths that constitute the phytocycle is one order of magnitude higher than those incoming and outgoing. The phosphorus cycling in the zone, therefore, can be considered closed.

The extent of the closure is higher in some ecosystems. For example, results compiled by Paul and Voroney for typical natural grasslands show that they have no output of phosphorus and that the accumulation of phosphorus in the soil is $0.05 \mathrm{gP} / \mathrm{m}^{2} / \mathrm{year}$, while the flow of phosphorus is $4.36 \mathrm{gP} / \mathrm{m}^{2} /$ year from inorganic to organic and $4.41 \mathrm{gP} / \mathrm{m}^{2} /$ year from organic to inorganic $/ 7 /$. This demonstrates not only closure but also a balance in the amount of material flow in natural ecosystems.

In clear contrast with the natural phosphorus cycling, the UK phosphorus economy is open and uneven. Every year, more than 100 kilotons of inorganic phosphorus is imported and used for agriculture, and 75 kilotons of organic phosphorus comes from overseas. Organic phosphorus excreted by donestic animals and humans goes largely to natural, soil microorganisms. Although soil microorganisms return $94 \mathrm{kilotons}$ of phosphorus in the form of inorganic phosphate to agricultural crops, man's heavy reliance on phosphorus mineralization by natural microorganisms might be imposing a stress to natural soil ecosystems. In fact, the phosphorus economy of Japan /8/ shows that 110 kilotons $P$ is the annual load from livestock and humans to natural soil microorganisms and the return to agriculture is $22 \mathrm{kilotons} / y e a r$. This imbalance must be a cause for the wide-spread eutrophication of waters in Japan.

The closure and the balance of material flows within a natural ecosystem have been also reported for nitrogen cyclings within mature ecosystems such as tallgrass prairie /9/ and northern hardwood forest $/ 10 \%$, while both sociogeochemical cyclings of carbon and of nitrogen exhibit the openness and the unevenness $/ 11 \%$ 


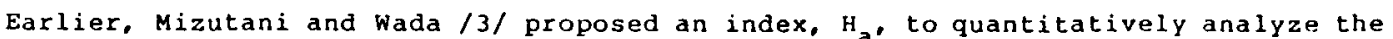
activity of life on the Earth. The index is a modification of Shannon's index of diversity, and the modification was specifically made to illustrate the importance of material flow and conversion in ecosystems. They made a preliminary analysis of global carbon cycling to evaluate the impact of man on the cycling. The earlier index was interested only in flows between groups within the system. However, in an actual ecosystem, inputs to and outputs from it also have a significant influence on the ecosystem. These flows must be especially important in the case of human intervention and of apparently open, natural ecosystems such as rivers, estuaries and rookeries /12,13/.

Therefore, it is proposed to include inputs and outputs in the index. The revised equation for the H-index is:

$$
H_{a}=-\sum_{i=1}^{N} \sum_{j=1}^{N} p(i, j) \log _{2} p(i, j) \quad \text { and } p(i, j)=\frac{f(i, j)}{\sum_{i^{\prime}=1}^{N^{\prime}} \sum_{j^{\prime}=1}^{N^{\prime}} f\left(i^{\prime}, j^{\prime}\right)}
$$

where a stands for a physicochemical species (or a group of species) of interest, $N$ for the number of groups of elements involved in the activities of transforming species a in an ecosystem, $N^{\prime}$ for the number of the groups including inflows and outflows, and $f(i, j)$ for the quantity of species a flowing from group $i$ to group j. A path within one group is defined as nonexistent: i.e., $f(k, k)=0$ for any $k$.

As $\mathrm{N}$ varies depending on each system of material cycling, so does the number of possible paths within it. In order to make a comparison between different systems, the index $H_{a}$ is divided by the maximum number the index can theoretically take.

The index after this normalization is: $\mathbf{B}_{\mathbf{a}}=\frac{\mathrm{H}_{\mathrm{a}}}{\mathrm{H}_{\max }^{\mathrm{Th}}}$

where $H_{\max }^{T h}$ is the maximum and is given by: $H_{\max }^{T h}=\log _{2} \mathrm{P}$

where $P$ is the number of paths present in the system.

The normalized index would be zero, when no flows between the groups in the system exist. And it becomes unity. when the material cycling within the system is completely closed and the amount of material flowing through each path is equal.

TABLE 1 Systems of Material Cycling and their H-index

\begin{tabular}{|c|c|c|}
\hline SPECIES & SYSTEM & $\mathbf{B}_{\mathbf{a}}$ \\
\hline CARBON & $\begin{array}{l}\text { WHOLE EARTH without human activity } \\
\text { with human activity }\end{array}$ & $\begin{array}{l}0.92 \\
0.53\end{array}$ \\
\hline PHOSPHORUS & $\begin{array}{l}\text { GRASSLAND } \\
\quad \text { with grazing } \\
\text { DECIDUOUS FOREST } \\
\text { EUTROPHIC LAKE } \\
\text { ECONOMY IN U.K. } \\
\text { ECONOMY IN JAPAN }\end{array}$ & $\begin{array}{l}0.94 \\
0.88 \\
0.95 \\
0.96 \\
0.63 \\
0.56\end{array}$ \\
\hline NTTROGEN & $\begin{array}{l}\text { WHOLE EARTH without human activity } \\
\text { with human activity } \\
\text { HARDWOOD FOREST } \\
\text { after deforestation } \\
\text { TALLGRASS PRAIRIE } \\
\text { with grazing } \\
\text { plus fertilizer } \\
\text { plus irrigation } \\
\text { SWAMP } \\
\text { MACARONI PENGUIN ROOKERY } \\
\text { KING PENGUIN ROOKERY } \\
\text { PADDY FIELD without fertilizer } \\
\text { with fertilizer } \\
\text { TOKYO BAY without human activity } \\
\text { with human activity }\end{array}$ & $\begin{array}{l}0.73 \\
0.61 \\
0.87 \\
0.72 \\
0.99 \\
0.76 \\
0.73 \\
0.69 \\
0.67 \\
0.15 \\
0.11 \\
0.13 \\
0.28 \\
0.23 \\
0.22\end{array}$ \\
\hline
\end{tabular}

$\mathbf{H}_{\mathbf{a}}$ was calculated from various published results. 
The normalized $\mathrm{H}$-index makes it possible to compare with one another apparently different systems of material cyclings such as the eutrophic lake and the UK phosphorus economy.

Results of a preliminary analysis of various material cycling systems taken from the literature are shown in Table 1. It is summarized as follows: a) For mature, natural ecosystems, $H_{a}$ is generally near unity; b) Human interventions to such systems decrease $H_{\mathbf{a}}$; c) Each species has its own characteristic behavior of $\mathbf{H}_{\mathbf{a}}$; d) $\mathbf{H}_{\mathbf{a}}$ of man-made systems is far below unity, probably because man is generally interested only in a portion of the whole material cyclings; e) For a paddy field that is an artificial, productive ecosystem, fertilization increases $\mathbf{H}_{\text {a }}$ and crop yield, while, for a natural prairie. human intervention decreases $H_{a}$; and $f$ ) For intrinsically open, natural ecosystems such as Tokyo Bay and seabird rookeries, $H_{a}$ is low even without human intervention.

The index, H, thus appears to characterize the nature of material cyclings within a system. It is a comprehensive measure for the productivity of a material cycling system, and, therefore, can be used to correlate the diversity of material flows with the stability and the productivity of ecosystems. It may be further applied to the development of an ecologically based 1 ife support system in space, and give a way to evaluate its ecological elements and its overall design.

\section{REPERENCES}

1. H. Mizutani, What is life? -changing view of man on life, in: Towards the 21st Century $=$ Life, Cells, and Genes, ed, T. Sato, Kogyo Chosakai Publishing Company. Tokyo 1985, p.265.

2. E.P. Odum, The strategy of ecosystem development, an understanding of ecological succession provides a basis for resolving man's conflict with nature, Science, 164. 262 (1969).

3. H. Mizutani and E. Wada, Material cycling and organic evolution, Oriqins of Life, 12. 369 (1982).

4. H. Mizutani, Cycles of life and man on the Earth, Future Biological Sciences Series, Kyoritsu Publishing Company, Tokyo, 1987, in press.

5. F.H. Rigler, Passage of phosphorus through a catchment, in: Environmental Biogeochemistry and Geomicrobiology, Volume 1: the aquatic environment, ed. W.E. Krumbein, Ann Arbor Science Publishers Inc.., Ann Arbor 1978, p. 65.

6. J.C. Bowman, Balance sheet for phosphorus in the UK, Phosphorus in the Environment: its Chemistry and Biochemistry, Ciba Foundation Symposium 57, Elsevier/Excerpta Medica/North-Holland, Ansterdam Oxford New York 1978, p. 243.

7. E.A. Paul and R.P. Voroney, Nutrient and energy flows through soil microbial biomass, Contemporary Microbial Ecology, 2nd International Symposium on Microbial Ecology, ed. D.C. ElIwood, M.J. Latham, J.N. Hedger, J.M. Lynch, and J.H. Slater, Academic Press, London 1980, p. 215.

8. H. Nishimura, Phosphorus cycle as a system, Chemistry Today, No.146, 59 (1983).

9. P.G. Risser and W.J. Parton, Ecosystem analysis of the tallgrass prairie: nitrogen cycle, Ecology, 63, 1342 (1982).

10. F.H. Bormann, G.E. Likens, and J.M. Melillo, Nitrogen budget for an aggrading northern hardwood forest ecosystem, Science, 196, 981 (1977).

11. H. Mizutani and E. Wada, Grasping the nature of material txansport in various ecosystems by the H-index, in: Abstracts of the 31st Annual Meeting of the Ecological Society of Japan. The Ecological Society of Japan, Matsumoto 1984, p.225.

12. H.J. Lindeboom, The nitrogen pathway in a penguin rookery, Ecology, 65, 269 (1984).

13. H. Mizutani, A chemical study on seabird rookeries - biogeochemical approach, Marine Sciences Monthly, 16, 226 (1984). 